\title{
Uzbek Diplomatic Speech Lexis' Semantic Relationship in Paradigmatic Lines
}

\author{
Nargiza Umarovna Kha \\ Uzbek Language and Literature Department, History and Languages Faculty, Tashkent region Chirchiq State Pedagogical Institute, Chirchiq \\ City, Uzbekistan
}

Email address:

Ms.Nargizaxanum@gmail.com

\section{To cite this article:}

Nargiza Umarovna Kha. Uzbek Diplomatic Speech Lexis' Semantic Relationship in Paradigmatic Lines. International Journal of Language and Linguistics. Vol. 8, No. 2, 2020, pp. 69-74. doi: 10.11648/j.ij11.20200802.12

Received: February 25, 2020; Accepted: March 11, 2020; Published: April 14, 2020

\begin{abstract}
Diplomacy and diplomatic relations are a practical field, which has its role and status from the moment of policy management in ancient time. For the Uzbek people, the concepts of diplomacy and diplomatic relations are not news. Its roots go back to the distant past - history. However, the appearance of the language depends on the process of speech and speech activity, where speech is based on a specific speech environment. Diplomatic activity exists only when the government becomes independent. Modern Uzbek diplomacy has been forming since 1991, when Uzbekistan gained independence. Since then, a great opportunity has appeared for the linguistic study of diplomatic speech at Uzbek language. The following problems became the main incentive for studying diplomatic speech based on a linguistic approach. 1. In books about Rhetoric, diplomatic speech is limited to one paragraph. 2. Examples presented as diplomatic discourse are often supplemented by excerpts from the speech of historical and creative heroes of historical works or fiction. 3. Real diplomatic speeches, demanded and understanding modernity, are not available from a scientific point of view. In search of a solution to these problems, on this article researched lexemes that form the basis of diplomatic speech by exploring their paradigmatic relationships. As a result, it was discovered that there are more than two hundred lexeme associated with diplomatic speech. When they were selected and classified, ten thematic groups were formed, which means paradigmatic rows. The main purpose of this article is to study each semantic relationship between members of this paradigmatic lines in a linguistic aspect.
\end{abstract}

Keywords: Diplomatic Speech, Paradigm, Lexeme, Integral, Differential, Privative, Attitude

\section{Introduction}

There are few scientific researching works about the development of diplomatic lexicon in the Uzbek linguistics. More over other searching works which exist till nowadays are extremely limited with their learning field. Among them we can count A. Orazboev [1], Z. Isakova [2], A. Turakhhodjaeva's [3] works.

In the dissertations of A. Orazboev and Z. Isakova had been studied the socio-political lexicon of a particular literary work.

In Turakhodjaeva's research, the socio-political lexicon of independence period was investigated.

In the process of system structural searching the diplomatic speech lexis, we focus on identifying the paradigmatic lines of this lexicon, to examine their semantic relationships in the paradigmatic rows. This will allow us to define quantity, size and usage area of the diplomatic speech lexicon. Due of paradigm's character, each diplomatic lexis row represented as a specific system. The diplomatic speech lexis of the Uzbek language can be placed in the following paradigmatic lines below.

\section{Paradigmatic Lines of Diplomatic Speech}

Diplomatic occupations, Diplomatic document, Diplomatic process, Diplomatic locality, Diplomatic Privilege, Addressing form of diplomatic speech, Diplomatic Relations, Diplomatic communications tool, Diplomatic membership, Public diplomacy. 


\subsection{Diplomatic Occupations}

Table 1. The paradigmatic row members of diplomatic occupations.

\begin{tabular}{|c|c|c|c|}
\hline 1. Agent & 2. Attaché & 3. Ambassador & 4. Consul \\
\hline 5. Delegator & 6. Delegation & 7. Diplomat & 8. Intermediary \\
\hline \multicolumn{3}{|c|}{ 9. Extraordinary and Plenipotentiary Ambassador } & 10. Minister \\
\hline 11. Negotiator & 12. Orderly & 13. Parliamentarian & 14. Prime minister \\
\hline 15. Press attaché & 16. Press secretary & 17. Representative & \\
\hline
\end{tabular}

According to the meaning structure of diplomatic occupations members are divided into two paradigms: 1) Expressions of pure diplomatic positions and 2) Positions which are near to diplomatic activities.

Compare: 1) Extraordinary and Plenipotentiary ambassador, diplomat, ambassador, consul, press attaché, attaché, parliamentary, orderly.

2) Agent, representative, intermediary, delegator, delegation, minister, prime minister, press secretary, negotiator.

Both groups' units form in paradigmatic line combining by diplomatic positions on the basis of integral meaning which called "sema". The lexemes of the first group have the sign "affirmed", so the first group have differentiation from the second. Thus, the $1^{\text {st }}$ and $2^{\text {nd }}$ semantic lines form in mutual privative contrary relation. The special peculiarity of the first line members is that the lexemes diplomat and the ambassador are placed at one line from the point of view of essence and value of the meaning, but looking their semantic structure it is difficult to say that these two lexemes are carrying equal value. The synonymic relation of diplomat with the ambassador are not recorded in any source [4].

This means that there was a quantitative change over the period. The lexemes diplomat and ambassador are similar and close in line with the general meaning of the term such as "the name of pure diplomatic position", "diplomatic status in the period of service", "person". At the same time these lexemes are differentiated according to their form and meaning. This differentiation is evaluating the equivalent opposition inside semantics of lexemes.

There is another difference in the semantic structure among the $1^{\text {st }}$ line members. The members of this line are stepping into the gradual contrast according to the semes that distinct "diplomatic status in the period of service". At the same time, Extraordinary and Plenipotentiary Ambassador and Orderly are making two polarity of opposition and create maximum contradiction.

The members between Extraordinary and Plenipotentiary Ambassador and Orderly are intermediate members.

\subsection{Diplomatic Document}

Table 2. The paradigmatic row members of diplomatic document.

\begin{tabular}{|c|c|c|c|}
\hline 1. Agrément & 2. Akkreditative certificate & 3. Agreement & 4. Communiqué \\
\hline 5. Contract & 6. Charter & 7. Declaration & 8. Doctrine \\
\hline 9. Decree & 10. Declarative statement & 11. Depeche & 12. Manifest \\
\hline 13. Memorandum & 14. Diplomatic passport & 15. Note & 16. Pact \\
\hline 17. Protest & 18. Protocol & 19. Ratification & 20. Sanction \\
\hline 21. Statement & 22. Treaty & 23. Trust symbol & 24. Ultimatum \\
\hline
\end{tabular}

This paradigmatic row contains three types of confrontation. The lexeme agrément according to the meaning of the "consent", while the protest and discord note units differ in terms of "resistance". Hence, these lexemes come into contact with each other on the basis of private contradictions. The lexemes treaty and agreement also coincide in the composition of the document by the participation of both sides. However, the sememe "stability" inside sememe treaty is different from the term "equality of interests" of the lexeme agreement. The terms "stability" and "equality of interests" create an equivalent contradiction.
In addition, in the analyzing line the term "the right to engage in diplomatic process" is an integral part of the units of the diplomatic passport and akkreditative certificate. Semantics all of other lexemes of the diplomatic document's paradigmatic row serve to regulate "diplomatic relations" during diplomatic activities. Diplomatic passport and akkreditative certificate can give the individual right to engage diplomatic activities by meaning "personal activity". This is the main difference between other units in the row. Because the other members of this line have not such meaning. These differences can be base for the separated contradiction.

\subsection{Diplomatic Process}

Table 3. The paradigmatic row members of diplomatic process.

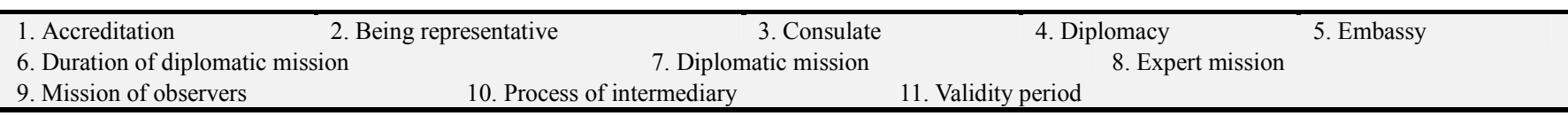


These paradigmatic units are different in semantic terms and form the following synonymic paradigm.

1) Duration: accreditation, validity period.

2) Process: process of representation, process of intermediary, diplomacy.

3) Mission: diplomatic mission, observer mission, expert mission.

4) Diplomatic mission: consulate, embassy.

Each semantic group of lexis in the field of diplomatic activity has the following paradigmatic relationships. The first accreditation and duration of diplomatic mission units will be in paradigmatic relation, interacting with the term "duration" in the diplomatic process.

Because, there term "duration" exists in both lexemes, the difference is that accreditation - "starting the diplomatic activity" and duration of diplomatic mission depends on the term "engaging in diplomatic activity throughout the whole period". In this case the term "duration" acts differentiated seme. The "shortness" duration in the term accreditation and the "continuity" in the meaning of the term duration of diplomatic mission stand in opposition and creates a relationship of controversy.

The members of the $2^{\text {nd }}$ line have a multidimensional contrary relation. The "sign of direction" in the semantics of this line has a distinctive and contradictory character. In the semantics of representation activity, the sign "direction" is unilateral, in the semantics of intermediary activities, the "direction" sign is bi-directional, and in the semantics of diplomacy, the "direction" is multidimensional, and these units have mutual differentiation.

Before examining the relationship between the lexeme of the $3^{\text {rd }}$ line, we define the explanation of the term mission: Mission - 1. High duty, responsible task. 2. Representatives who is sent to another country by a specific task. 3 . Permanent diplomatic representation of a State in another country (not look like the embassy) or representative in international organizations [5]. So diplomatic mission has the meaning of high responsibility. Observers' mission and expert mission - have meaning the delegates sent to another country by a specific mission.

The term "high duty" in these units is differential sema, while at the same time it formulating a relationship of private contradiction. The members of these paradigmatic units observers' mission and experts' mission create a paradigm of mutual content. But the difference between them is based on the type of activity of these syntactic units. Specifically, there is an observer activity in the observers' mission and expert activity has shown in experts' mission. The contradiction between these units is based on the differential features among them. Thus, according to the diversity of the activity, the same units attach to the equivalent contrary relation.

In the $4^{\text {th }}$ line the sema of diplomatic mission serves as an invariant for embassy and consular lexemes with a "high duty", "responsible task". Thus, this line has complete and fragmentary relationship; the diplomatic mission is the option for the lexeme of "mission" according to the participation at the $3^{\text {rd }}$ synonym paradigmatic line, at the $4^{\text {th }}$ line it is invariant for the types of diplomatic activity, such as embassies and consulates.

\subsection{Diplomatic Locality}

Table 4. The paradigmatic row members of diplomatic locality.

\begin{tabular}{lll}
\hline 1. Agency & 2. Consular office & 3. Embassy \\
4. Headquarters' flat & 5. Ministry & 6. Ministerial \\
7. Place of residence & 8. Representative office & \\
\hline
\end{tabular}

The lexemes of this paradigmatic row is characterized by affixes differentiation. Compare: 1) with the suffix "...lik" in Uzbek: agentlik, vazirlik, vakillik; in English: "-cy, -y, -ty": agency, ministry, authority.

2) with the suffix "... xona" in Uzbek: vakolatxona, konsulxona; in English: representative office, consulate, embassy. These two types of paradigm line are integrated into a paradigm based on "building" and "locality". At the same time, these units are differentiated according to the suffixes. Suffixes create a contradictory relation between these members. More specifically, this contradiction becomes more apparent when the role of suffixes changed. Compare: 1) agentlik, vazirlik, vakillik - agentxona, vazirxona, vakilxona. The syntactic relationship by suffixes at this row member are not relevant to the requirement; they are forms of expression that are contrary to the nature of the Uzbek language. 2) vakolatxona, konsulxona - vakolatlik, konsullik. In the second row were a semantic change in the lexis of the line. New creating words vakolatlik and konsullik (representation and consul) did not carry mean "locality", they meant "diplomatic activity".

In the paradigmatic area of diplomatic locality, units such as headquarters and place of residence have a common sense. At the same time, they are different for their belonging to different languages. Compare: "shtab kvartira" [6] the headquarters apartment is belonging to German language and the "qarorgoh" [7] - residence is belonging to Arabic, Persian-Tajik languages.

\subsection{Diplomatic Privileges}

Table 5. The paradigmatic row members of diplomatic privileges.

\begin{tabular}{lll}
\hline 1. Accreditation & 2. Career & 3. Diplomatic empowerment \\
4. Diplomatic & 5. Diplomatic & 6. Rank \\
inviolability & immunity & . \\
\hline
\end{tabular}

The units of this paradigmatic row united according to their integral seme "having diplomatic privileges right", but they are differentiated by what kind of privileges they mean. For example, accreditation and diplomatic empowerment, diplomatic inviolability and diplomatic immunity, career and rank. Accreditation - Head of the Diplomatic Agency or Permanent Representative of the State to any International Organization [8].

Diplomatic empowerment - means the privileges that are used throughout the term of diplomatic activity [9]. This means that accreditation and diplomatic empowerment - 
through "empowerment", "permanent" semes have a general meaning. Their difference is determined by the term of duration of empowerment. In fact, there is "shortness" in the accreditation semantics, and the semantics of the diplomatic empowerment has the meaning "continuity".

The explanation of syntactic units' diplomatic inviolability and diplomatic immunity are below:

Diplomatic inviolability - is the protection from any threat or aggression [10]. Diplomatic Immunity - special rights and privileges used by diplomatic agencies and their staff of foreign states [11].

The semantics of those words are differentiated as diplomatic inviolability according to the semantics of the term "protected" and diplomatic immunity according to the term "legitimacy".

The lexemes career and rank each has common feature according to express diplomatic status and degree of the title. However, lexeme rank differs from the lexeme career according to the narrow band area of usage. To sum up, component analyzing units of paradigmatic line creates private contradiction.

\subsection{Addressing Form of Diplomatic Speech}

Table 6. The paradigmatic row members of addressing form of diplomatic speech.

\begin{tabular}{llll}
\hline 1. Graf & 2. Countess & 3. Mr. & 4. Mister \\
5. Your Excellency & 6. Miss & 7. Mrs & 8. Pan \\
9. Senor & 10. Senora & 11. Lady & 12. Ambassador \\
13. Khonim & 14. Janob & 15. Gentleman & \\
\hline
\end{tabular}

The units that form the paramagnetic sequence vary primarily from gender type relations. This distinction is made according to the gender identity of "feminine" and "masculine". Consequently, two internal semantic groups are formed. Compare: 1) Female: Countess, Mrs., Miss, Your Excellency, Senora, Lady, Khonim (in Uzbek language). 2) Male: Graf, Mr., Mister, Gentleman, Your Excellency, Senor, Ambassador, Pan, Janob (in Uzbek language).

The "female" and "male" contradictions belong to all of the following units and create multidimensional contradictions as a result on the basis of the "female" and "male" sign. Even though each member of two paradigms group has equivalence contradiction, there is a proportional contradiction also available. The proportional contradiction will have seen between members of one paradigm. For example, $M r$. and Mister.

Some pairs in the common paradigm line members have distinction with their similarity of shape and being appropriate to one language.

Compare: the lexemes of Senor and Senora are related to Italian, Khonim (Lady) and Janob (Gentleman) in Uzbek, Miss and Mister, Lady and Gentleman are belonging to English [12].

Hence, pairs differ from meaning in general and private according to terms of their belongings to different languages. The lexeme Pan which is in paradigmatic line is a word which means "Mr." when this word is addressed to men in a number of Eastern European countries [13]. At the same time, the word Pan has the same meaning as $M r$. So, in members of those paradigmatic line observed variation attribute due of their unity of a content and meaning.

\subsection{Diplomatic Relations}

Table 7. The paradigmatic row members of diplomatic relations.

\begin{tabular}{lll}
\hline 1. Consular relations & 2. Interstate & 3. International \\
4. Partnerships & 5. Intergovernmental & \\
\hline
\end{tabular}

The paradigmatic relationships of the units which mentioned name above are divided into two synonym paradigms. 1) Interstate, international, intergovernmental. 2) consular relations, partnerships. The lexical units in the first line have the same commonality as "mutual" and "belongingness". The semantics of state and government lexemes are semantic synonyms according to the sign of "governance". There is no such sign in the public lexeme.

Thus, the units of synonym paradigm form contradictory relationship with respect to the differential semantics of "governance". Interstate and international units have a syntactical relationship with the lexeme of "relation". Compare: Interstate relations, International relations. At the same time, the notion of "diplomatic relations" is more precisely described in the combination of international relations. Consular relations and partnership relationships are belonging to concrete consular relations.

In this case, concreteness in this relation appears according to the consular lexeme. The concept of relationships in the partnerships relations is relatively abstract. This abstract is based on the phrase "two sides" in the partnership lexeme. Nevertheless, the type of relationship remains abstract with the participation of "the two sides". The members of this paradigm are in private contradictory relation according to the differential sign of "concreteness".

\subsection{Diplomatic Communications Tool}

Table 8. The paradigmatic row members of diplomatic communications tool.

\begin{tabular}{ll}
\hline 1. Diplomatic correspondence & 2. Internet network \\
3. International languages & 4. Esperanto \\
\hline
\end{tabular}

They are: diplomatic correspondence, internet network, international languages and Esperanto are connected according to integral semantics of "diplomatic communication".

In the group of diplomatic correspondence and the internet network, the combination of diplomatic correspondence is distinguished by mainly in "paper" version, and the Internet in the "electronic" version. Conditionally, it is possible to transform the combinations of "diplomatic correspondence" and "internet network" as "paper correspondence" and "electronic correspondence". Then, the difference between these syntactic units would be clear. Thus, there will be private contradictory relation in combinations of diplomatic correspondence and internet network based on the "electronic" sign, which is the basis for the differentiation. 
Esperanto and international languages are the common means of communication at the diplomatic speech, in contrast their different aspects depending on their composition and use. In fact, Esperanto is an artificial language that is rarely used at speech, international languages are naturally used in the process of speaking as the most important and basic communication tool of society. Accordingly, they are dealing with private contradictory relation.

\subsection{Diplomatic Membership}

Table 9. The paradigmatic row members of diplomatic membership.

\begin{tabular}{lll}
\hline 1. Association & 2. Alliances & 3. Corpus \\
4. Community & 5. Society & 6. Union \\
\hline
\end{tabular}

The paradigmatic line of diplomatic membership is integrated and interconnected through the integral seme of "uniting under the one purpose".

Each paradigm unit is differentiated by the difference between "quantity" and "scale". Association and Union. The number of members (individuals) included in the association lexeme is a "minority" than the lexeme of union. If in the semantics of the association are united the group of people or public organization, for example: Association of the Electronic Mass Media and the semantics of union are united by a number of states, such as the European Union. So, these lexemes are linked together in a complete and fragmentary manner.

Moreover, the quantity in the lexeme of association takes the whole function for the lexeme of society. Specifically, while the semantics of society represent a unity of people, for example: Society of the Blind and in the semantics of association we can observe unity of number of societies. For example, the Association for the Disabled. Society association - union lexemes are stepping into the gradual contradiction in terms of the "quantity" sign. The society and the union lexemes constitute the boundary members of the contradiction.

The members of the corpus and association paradigm are general according to referring the "a group of targeted people". However, the corpus lexeme differs from the lexeme of association by a syntagmatic relationship with the diplomatic lexeme. Compare: 1) Diplomatic corpus. 2) Diplomatic Association. But, the combination of diplomatic association does not use at diplomatic speech. Accordingly, these units are included to mutual private relation.

\subsection{Public Diplomacy}

Table 10. The paradigmatic row members of public diplomacy.

\begin{tabular}{lll}
\hline 1. Match-making & 2. Diplomacy & $\begin{array}{l}\text { 3. Slavery (a type of public } \\
\text { diplomacy that is similar with } \\
\text { match-making) }\end{array}$ \\
\hline
\end{tabular}

Public diplomacy is characteristic of the Uzbek people as an informal diplomacy. The following definition for this concept is given in the explanatory dictionary: "Informal activities aimed at addressing the pressing social problems of some people, social groups, and others" [14]. The meaning of public diplomacy is composed from interconnected components such as "some individuals", "solving actual social problems" and "strengthening mutual cooperation".

Paradigmatic line of public diplomacy differs from other paradigmatic lines of diplomatic activity. It's being related to domestic issues not intergovernmental. Paradigmatic line of public diplomacy consists of lexemes as: match-making "sovchilik", diplomacy "elchilik", slavery "qulchilik" [15]. These sequences of units are the lexemes of the national traditions of the Uzbek people and they stand in one paradigmatic line, due to the seriousness and sophisticated nature of the issue and taking care of the interests of the parties, requires prudence and culture in relationships.

The lexeme slavery refers to the Uzbek character of the speaker, the humility of his speech. This process appears as a kind of form of match-making activity. Compare: We visited your house to be a slave - "qulchilikka keldik".

The lexeme match-making has a positive connotative statement. Compare: We came to match-making "sovchilikka keldik".

The lexeme to make diplomacy is a sophisticated feature of the speech, which shows the simplicity and sincerity of the other side in match-making. Compare: We have come to make diplomacy - "elchilikka keldik".

The similarity, closeness and general features of the units are explained by the term thatch-making." Different aspect is that the aesthetic coloring of every single lexeme is determined by the presence of a connotative expression. Hence, the paradigmatic lines are in the level of mutual contradiction.

Among the semantics of lexemes as match-making "sovchilik", diplomacy, "elchilik", slavery "qulchilik" - in the lexeme slavery the connotative expression is strong, and in the lexeme of the diplomacy it is weaker than it, and there is no such expression in the lexeme match-making. Slavery and match-making are the boundary pole of contradiction. Multidimensional contradiction is peculiar for this paradigmatic line.

\section{Conclusion}

The lexemes of Uzbek language for diplomatic speech established in ten paradigmatic rows. These paradigmatic lines also have mutual and private aspects, with different semantic relationships between their internal members. Members of the paradigm represent the nature and specificity of the Uzbek diplomatic speeches due to their function and application.

1) The lexems ambassador and diplomat are similar with seme "purely diplomatic activities", "diplomatic careers" and "person". Based on this analysis the words ambassador and diplomat are recommended to be understood as synonyms at Uzbek language.

2) The semantics of the lexems diplomatic passport and akkreditative certificate with the designation 
"diplomatic activity" and more specifically "personal activity" is separate from entire paradigmatic row denoting diplomatic documents.

3) The semantic nature of representative, intermediary activities and diplomat were clearly defined in accordance with the sign of "direction".

4) The nature of lexical units in the paradigm of diplomatic locality depends on the activity of the word forming components, which are significant only for the Uzbek language.

5) The addressing form of diplomatic speech was first manifested in the opposition by the pairwise combination between the members of the paradigm.

6) The paradigmatic line of addressing form of diplomatic speech is formed as a component element of gender linguistics.

7) The concepts of "diplomatic relations" and "diplomatic communications tool" are clearly differed.

8) The row of public diplomacy has analyzed and presented the formal aspects of informal diplomacy.

\section{References}

[1] Orazboev., A. D. Socio-political lexics in Ogahi's work «Riyaz ud-davla» Dissertation for candidate of philolgical sciences. - Tashkent, 2009. P-155.

[2] Isaqova., Z. M. Socio-political lexics in of Alisher Navoi's work «Majolis un-nafois» Disseration for candidate of philolgical sciences. -Tashkent, 2010. P-166.
[3] Turakhodjaeva., A. X. Development of socio-political lexicon of Uzbek language in Independence period. Dissertation for candidate of philolgical sciences. -Tashkent, 2012. P-136.

[4] Hojiev., A. Explanatory dictionary of the Uzbek language synonyms. - T.: Teacher, 1974. $-307 \mathrm{p}$.

[5] Explanatory Dictionary of the Uzbek language, Volume 2. T.: National Encyclopedia of Uzbekistan, 2006. p. 601-602.

[6] Explanatory Dictionary of the Uzbek language, Volume 4, p. 601-602.

[7] Explanatory Dictionary of the Uzbek language, Volume 5, p. 251.

[8] Explanatory Dictionary of the Uzbek language, Volume 1, p. 62.

[9] Explanatory Dictionary of the Uzbek language, Volume 1, p. 437.

[10] Explanatory Dictionary of the Uzbek language, Volume 1, p. 577-578.

[11] Explanatory Dictionary of the Uzbek language, Volume 2, p. 202.

[12] Explanatory Dictionary of the Uzbek language, Volume 2, p. 602.

[13] Explanatory Dictionary of the Uzbek language, Volume 3, p. 211.

[14] Explanatory Dictionary of the Uzbek language, Volume 1, p. 624.

[15] Special kind of phrases which are characteristic to Uzbek national traditions. 